\title{
Palliative Care in Acute Heart Failure
}

\author{
James M. Beattie ${ }^{1}$ (D) - Irene J. Higginson ${ }^{1}$ - Theresa A. McDonagh ${ }^{2}$
}

Accepted: 15 October 2020 / Published online: 29 October 2020

(C) The Author(s) 2020

\begin{abstract}
Purpose of Review Palliative care is increasingly acknowledged as beneficial in supporting patients and families affected by heart failure, but policy documents have generally focused on the chronic form of this disease. We examined palliative care provision for those with acute heart failure, based on the recently updated National Consensus Project Clinical Practice Guidelines for Quality Palliative Care.

Recent Findings The commonest reason for hospitalization in those $>65$ years, acute heart failure admissions delineate crisis points on the unpredictable disease trajectory. Palliative care is underutilized, often perceived as limited to end-of-life care rather than determined by regular systematic needs assessment. No dominant paradigm of palliative care provision has emerged from the nascent evidence base related to this clinical cohort, underscoring the need for further research.

Summary Embedding palliative support as mainstream to heart failure care from the point of diagnosis may better ensure treatment strategies for those admitted with acute heart failure remain consistent with patients' preferences and values.
\end{abstract}

Keywords Palliative care $\cdot$ Acute heart failure $\cdot$ Needs assessment $\cdot$ End-of-life-care

\section{Introduction}

Heart failure (HF) is a modern epidemic affecting close to 40 million people worldwide. The Rotterdam study estimated the prevalence to be about $2 \%$ in the general population, rising to $17.4 \%$ in those aged $\geq 85$ years [1]. Linked to societal aging and also improved treatments for a range of cardiovascular diseases, projections have suggested a $46 \%$ increase in the prevalence of HF between 2012 and 2030 [2]. The incidence of HF is equivalent to the combined incidence of four common cancers - lung, breast, bowel, and prostate [3] - and the lifetime risk appears to be similar at 1 in 5 for both men and women. However, for men the incidence doubles during each decade between 65 and 85 years, while for women the

This article is part of the Topical Collection on Decompensated Heart Failure

James M. Beattie

jmbeattie@ hotmail.com

1 Cicely Saunders Institute of Policy and Rehabilitation, King's College London, London, UK

2 School of Cardiovascular Medicine and Sciences, King's College London, London, UK incidence trebles over the same age deciles [4]. Heart failure is the commonest reason for hospital admission in those aged $>65$ years, this inpatient care accounting for much of the expenditure required to treat this condition, the annual cost estimated to be at least US\$108 billion for health economies globally [5].

Heart failure results from a diverse range of etiological cardiovascular conditions causing a spectrum of systolic and diastolic dysfunction, often mediated by disparate patterns of ventricular remodeling. The Heart Failure Association (HFA) of the European Society of Cardiology (ESC) has characterized three HF phenotypes based on assessment of left ventricular ejection fraction (EF) [6]: HF with a reduced $\mathrm{EF}$ (HFrEF), when the $\mathrm{EF}$ is $<40 \%$, HF with a mid-range or mildly reduced EF (HFmrEF) [EF 40-49\%], and HF with preserved EF (HFpEF) $[\mathrm{EF} \geq 50 \%]$ respectively. The clinical presentation is similar across this HF phenotypic spectrum, the diagnosis usually considered in people presenting with effort dyspnea or orthopnea, easy fatiguability, and exhibiting a collection of stereotypical clinical features.

Heart failure can develop insidiously, or other patients present in an emergent fashion with de novo acute HF (AHF), when rapidly progressive symptoms and signs develop over a short period. AHF accounts for only about one-third of all $\mathrm{HF}$ admissions, the majority associated with acute decompensation of chronic HF (ADCHF) [7], and it has been 
argued that these clinical presentations should be regarded as distinct clinical entities. In a recent study of 370 consecutive patients hospitalized with dyspnea, echocardiographic evidence of left ventricular dysfunction, and elevated NTproBNP, ADCHF was diagnosed in $80 \%, 62 \%$, and $28 \%$ of those with HFrEF, HFmrEF, and HFpEF respectively [8].

It is beyond the scope of this review to describe the treatment of acute HF in detail, but as outlined in recent clinical guidelines, the required pharmacologic approaches and other measures are defined by congestion and hypoperfusion profiling (warm and wet or cold and dry) [6, 9]. Congestion demands the use of loop diuretics by a variety of dosing regimens. Other patients require vasodilator, inotropic or vasopressor therapy, these latter treatments not without risk. Increasingly, further intervention includes non-invasive ventilation, while intubation for mechanical ventilation, the use of extracorporeal membrane oxygenation (ECMO) or mechanical circulatory support (MCS), necessitates admission to a cardiovascular intensive care unit (ICU). Close monitoring is required, and a recent American College of Cardiology expert consensus document elegantly describes risk assessment and decision making relevant to the management of such patients [10॰]. An inadequate response to therapy or in-hospital worsening of HF auger a poor prognosis [11]. Based on the National Heart Failure Audit (NHFA) data for 68,266 adults admitted with HF to hospitals in England and Wales between April 2017 and March 2018, 66\% with HFrEF, the inpatient mortality was $10.1 \%$ [12]. In EuroHeart Failure Survey II, the in-hospital mortality was greater for AHF at $8.1 \%$ compared to $5.8 \%$ for ADCHF [13]. In contrast, a non-fatal admission with ADCHF portends worse intermediate and long-term outcomes. These patients have a longer duration of documented $\mathrm{HF}$ and are often older with more comorbidities. Earlier NHFA data suggested a 1-year all-cause mortality of $56 \%$ for those aged $>75$ years [14].

Depending on the underlying etiology, appropriately treated acute ventricular dysfunction may recover in so-called myocardial remission, but the majority surviving the index acute phase go on to develop chronic HF. Thereafter, the clinical course is similar to other life-limiting diseases such as chronic obstructive pulmonary disease (COPD) or renal failure, typically manifest in a roller coaster disease trajectory with a pattern of gradual decline, interspersed with inflection points marking ever more frequent acute clinical crises. These include those related to ADCHF, sometimes evident in a sentinel cluster of hospital admissions close to the end of life [15]. Cardiovascular causes of death predominate, and while lethal arrhythmia as a mode of dying is diminishing, this still accounts for $17 \%$ of all fatalities within 30 days of an admission for ADCHF [16, 17]. Heart failure patients surviving 3-5 years out from their initial diagnosis increasingly die from unrelated comorbidities such as cancer, and indeed various serological factors directly linked to the HF state may be implicated in tumorigenesis [18].

\section{Palliative Care and Heart Failure}

Evolving from the hospice movement of the 1960s and 1970s, palliative care (PC) is regarded as an essential component of universal health coverage. The most widely accepted definition is from the World Health Organisation (WHO) which in 2002 [19] described this as:

..an approach that improves the quality of life of patients and their families facing the problems associated with life-threatening illness, through the prevention and relief of suffering by means of early identification and impeccable assessment and treatment of pain and other problems, physical, psychosocial and spiritual.

Originally closely aligned to oncologic practice, over the past 20 years or so, with increased awareness that the PC needs of those living with HF or cancer are similar [20, 21], HF has been in the vanguard of extending this support beyond that founding base. Palliative care is now incorporated within national and international HF treatment guidelines [6, 22], and has been the subject of recent position statements by the ESC HFA and the European Association of Palliative Care (EAPC) $[23 \cdot \bullet, 24 \cdot \bullet]$.

To some extent, the features of PC as described by the WHO are central tenets of all clinical practice, and essentially any clinician should be able to offer so-called generalist or primary PC in providing basic symptom control, elucidating goals of care, and enabling clinical coordination. Indeed, a combination of primary and specialist PC has been posited as a potential sustainable model of HF PC service provision [25]. However, the skillset of PC specialists facilitates more comprehensive and effective targeting of complex physical symptoms and the psychological or existential distress commonly affecting those with this significant disease, their care needs often beyond the tacit knowledge and experience of HF professionals. Good communication is central to the practice of $\mathrm{PC}$, and integrating such professionals within a multidisciplinary team (MDT) fosters shared decision making to better ensure that established or proposed elements of guidelinedirected medical therapy (GDMT) remain consistent with patients' and families' goals of care, preferences, and values, often subject to change in the face of disease progression.

It is important to emphasize that including PC in the treatment strategy from the initial diagnosis of $\mathrm{HF}$ is not at odds with the co-provision of life-prolonging therapies from that point and throughout the disease trajectory, this professional collaboration continuing beyond the death of patients in affording supportive care to their bereaved relatives or other close persons [26••]. Thus, PC should not be regarded as limited to end-of-life care which constitutes just one of eight domains defining core standards of clinical practice by the National Consensus Project for Quality Palliative Care [27] 
(Table 1). We shall base this review of PC for acute HF on this suite of quality domains.

\section{Structure and Processes of Care Provision}

Integrating PC within HF services depends on the configuration of national and local healthcare structures and is contingent on the organizational frameworks underpinning clinical care, including regulatory systems defining care eligibility and reimbursement. There is wide disparity internationally [28]. For example, in the United States (US) as of $2018,50 \%$ of hospitals with $\geq 300$ beds offered specialist PC consultations to adult inpatients, a service less accessible in Europe, although 8 European countries have established fully integrated HF PC services [29, 30]. On the African continent where the prevalence of $\mathrm{HF}$ is rising, this constitutes the commonest cardiovascular condition requiring hospitalization. While some African countries have adopted national PC policies, even when such services do exist, resources are limited, with scant data on HF-related service structures [31].

As the applicability of PC for HF has gained traction in recent years, hospital admission has been specifically cited as an opportunity to integrate this form of support [32], but incorporating this as standard care remains difficult, particularly for those with acute HF syndromes [10•]. Palliative care involvement during unplanned hospitalizations is exceptional, and in North America, this has been documented at only $3.9 \%$, even in those patients requiring mechanical ventilation $[33,34]$. For England and Wales, NHFA data have demonstrated that only $3.1 \%$ of acute $\mathrm{HF}$ patients were referred to $\mathrm{PC}$ at their index admission, this rising to $7.3 \%$ following readmission [35]. Similarly, registry data from Sweden recorded that just $4.2 \%$ of HF decedents received such support during their last week of life [36].

Many factors contribute to this relative lack of PC engagement [37]. The landscape of cardiovascular clinical practice is dominated by the rule of rescue in preserving life at all costs, prompting a sense that the need to consider PC implies

Table 1 Key domains for quality palliative care

Structure and processes of care provision

Addressing physical symptoms

Psychological and psychiatric care

Social care

Spiritual, religious, and existential support

Culturally competent care delivery

Care near the end of life

Ethical and legal constructs relevant to care

Based on the National Consensus Project Clinical Practice Guidelines for Quality Palliative Care, 4th Edition. (Modified from Ferrell et al. [27]) professional failure. Cardiology professionals often shy away from opening conversations to explore treatment preferences and the applicability of PC in the face of clinical decline, concerned this discourse might undermine patients' and families' trust, and dash their hopes for the future [38]. A misconception still prevails that PC is limited to end-of-life care.

Despite the uncertainty intrinsic to the HF disease trajectory, prognostication has often dominated consideration for PC involvement. As with chronic HF, multivariate risk scores for acute HF populations have also been developed [39], but prognostication for individual patients is still challenging. The surprise question ("Would you be surprised if this patient were to die over the next year?") has been shown to have a sensitivity and specificity of $85 \%$ and $59 \%$ respectively for acute HF inpatients when used by HF specialists, but performance declines with less experienced staff, and judgment based on this approach remains largely intuitive [40]. Although some clinical descriptors of advanced (Stage D) HF predict mortality risk, these show poor correlation with symptomatic status, and we would argue that the requirement for PC support should be judged on the basis of systematic needs assessment rather than prognosis [41].

Patient-reported outcome measures (PROMs) characterize the experience of those living with conditions such as HF, enabling clinicians to be attentive to the often-nuanced needs of each patient, and to assess changes over time or following interventions. Their use facilitates person-centered care. To be effective, PROMs must exhibit robust psychometric properties, demanding rigorous verification of reliability and reproducibility, validity, responsiveness, and acceptability. The most widely adopted HF-specific PROMs are the selfadministered 21-item Minnesota Living with Heart Failure Questionnaire (MLHFQ) and the 23-item Kansas City Cardiomyopathy Questionnaire (KCCQ). The MLHFQ and KCCQ incorporate multiple domains using Likert scales to quantify the presence and severity of physical symptoms, and any psychosocial impact. Other instruments are more geared to evaluate PC needs. Based on estimating symptom burden, the 10-item Edmonton Symptom Assessment System (ESAS) also uses numeric rating and has been subject to significant modification since first developed in 1991 [42]. The Functional Assessment of Chronic Illness Therapy-Palliative Care (FACIT-Pal) Scale is a 46-item self-reported measure appraising physical, social, emotional, and functional well-being, and incorporating a 19-item PC subscale assessing symptoms, social interaction, and meaning in life [43]. The 10-item Integrated Palliative care Outcome Scale (IPOS), which is freely available (www.pos-pal.org), has also been demonstrated as feasible and acceptable in the comprehensive assessment of HF symptoms, and to be deliverable by HF nurse specialists after appropriate training [44•]. Developed in Australia, a HFspecific instrument, the Needs Assessment Tool: Progressive Disease-Heart Failure (NAT: PD-HF) aids assessment of the 
physical and psychosocial well-being of both HF patients and their informal carers across a range of care settings, defining thresholds of concern useful in delineating those in need of specialist involvement [45 ]. Both the IPOS and NAT: PD$\mathrm{HF}$ instruments have been utilized in those admitted with acute HF $[46,47]$.

Most randomized clinical trials (RCTs) of HF PC have been carried out in North America and Northern or Western Europe, much of this work focused on chronic HF. While the evidence base remains relatively light across an array of interventions subject to various assessment methodologies, recent meta-analyses suggest that this support improves HF patients' quality of life (QoL) and reduces their symptom burden, with no adverse effect on mortality $[48 \bullet, 49 \bullet \bullet]$. The reported impact on rehospitalization rates is mixed, this varying between a neutral effect or significant reduction.

Hospital-based PC teams likely improve care for those affected by a variety of underlying diagnoses, and particularly relevant to this review, several studies have purposely examined the effects of a PC intervention for people admitted with acute HF. Based in a tertiary-care urban hospital setting, Sidebottom and colleagues compared outcomes in 232 patients randomized to receive standard care with or without an initial inpatient PC review, followed by additional consultations at 1 and 3 months post-discharge [50]. Patients randomized to the PC treatment arm had greater alleviation of symptoms as evaluated by ESAS and the Patient Health Questionnaire-9, with increased participation in advance care planning (ACP), and no significant effect on hospice use, 30day readmission rates, or mortality.

Hopp et al. studied 85 urban-living patients, predominantly African Americans, admitted with ADCHF, and randomized to a PC consultation in addition to usual care [51]. There were no significant inter-group differences for the primary endpoints in choosing a "Do not attempt cardiopulmonary resuscitation" (DNACPR) policy during the index or later hospitalizations, or their preferences for comfort care, including the use of hospice post-discharge. Of this study cohort, $23.8 \%$ died within 3-6 months of randomization and the PC intervention did not influence survival.

The landmark Palliative Care in Heart Failure (PAL-HF) trial was a single-center unblinded RCT undertaken at Duke University Hospital in Durham, NC [52••]. This involved HF inpatients recruited within $48 \mathrm{~h}$ of planned discharge $(n=148)$ or within 2 weeks of hospital discharge $(n=2)$, deemed to be at high risk of rehospitalization or death. The primary study objective, coordinated by a PC nurse practitioner, was to examine the impact on health-related QoL of a supplementary multicomponent PC intervention, delivered by an MDT after discharge, in addition to usual care. As outlined in the trial protocol, the PC intervention targeted symptom relief, spiritual concerns, and ACP. Over a 6-month period post-discharge, patients randomized to the PC group had significant improvements in
KCCQ and FACIT-Pal scores compared to those receiving usual care, these benefits more obvious in men. Positive effects on secondary endpoints included better spiritual well-being and less anxiety/depression. There were no demonstrable effects on rehospitalization rates or mortality. In PAL-HF, the benefits of PC continued throughout the observational period of the study; however, other reports suggest early gains evident after initiating inpatient PC support might wane over time [53].

Wong and colleagues compared outcomes of a transitional PC model on 84 recently discharged HFrEF patients, judged by their clinicians to be in the last year of life [54]. In this multi-site RCT based in Hong Kong, following pre-discharge assessment, PC nurse case managers, supported by a PC physician within an MDT process, undertook weekly home visits/ telephone consultations over a 4-week period, followed by regular contacts through 12-months follow-up. For the intervention group, the primary endpoint of readmission rate was significantly reduced. They also showed improved secondary outcomes with reduced symptom intensity as measured by ESAS, and improved QoL when assessed by validated Chinese versions of the Chronic Heart Failure and McGill Quality of Life Questionnaires.

The Social Worker-Aided Palliative care intervention in highrisk patients with Heart Failure (SWAP-HF) is a recent prospective RCT conducted at the Brigham and Women's Hospital in Boston, MA [55]. This study involved 50 high-risk ADCHF patients recruited during admission or shortly thereafter, randomized to intervention or usual care. Over a 6-month period postdischarge, a PC-trained social worker led conversations with the intervention group, evaluating their symptom burden, QoL, patients' and families' understanding of prognosis, and their preferences for end-of-life care, coordinating review by a PC physician as necessary. A higher proportion of the $\mathrm{PC}$ group had more realistic understanding of their prognoses, these better aligned with their physicians' opinions, and there was more documentation of ACP and end of life treatment preferences compared to those receiving usual care, this information readily accessible to non-study staff in patients' clinical charts. There were no adverse outcomes in relation to depression/anxiety, spiritual distress, or worsening KCCQ scores.

Insofar as the above RCTs appear to show a relative uniformity in positive outcomes across the spectrum of PC interventions offered to these acute HF cohorts, we must add a caveat that, in the main, usual care was not systematically described in these studies, and may have been heterogeneous both within single centers and between sites. Palliative care interventions are relatively complex, and recent work has proposed a means of classification of usual care which might better assure the validity of perceived outcomes [56].

As apparent in the studies described above, no dominant model of the integration of PC support for HF inpatients has emerged. Hospital-based PC services might be provided using on-site beds assigned to PC, but perhaps more commonly, this 
care element is made available to those occupying ICU, acute, or sub-acute beds through an advisory or consultative in-reach service involving specialist PC physicians or nurses.

Collaborative MDT working is considered central to the co-management required of effective HF PC provision. The MDT membership will vary between organizations, and the array, weighting, and means of delivery of specific care constituents will also be determined by individual patients' needs in relation to their heart disease, comorbidities, sociocultural characteristics, and health literacy. Productive MDT activity requires agile and responsive processes, and within this construct, it is clearly important to undertake task allocation and define the responsibilities of team members. It may be helpful to designate one individual to act as interlocutor, liaising with the patient, family, and any contributing external agencies to foster good communication and care coordination between acute, ambulatory, and community-based services. Transitions between treatment settings present particular risks of care fragmentation [57]. It is important to ensure continuity of care with robust systems of information transfer, and the ready availability of professional advice and access to $\mathrm{HF}$ therapies for patients discharged from hospital to their own home or care home, to a skilled nursing facility, or a hospice.

\section{Addressing Physical Symptoms}

Optimal GDMT improves longevity, and those adhering to this may also experience symptomatic benefit. However, for many HF patients now living longer with this progressive condition, survivorship becomes manifest in a fairly liminal existence, burdened by a constellation of refractory symptoms, comprehensively described elsewhere [58•]. Indeed, based on the Evaluation Study of Congestive Heart Failure and Pulmonary Artery Catheter Effectiveness (ESCAPE) sub-study, following hospitalization with ADCHF, some patients might be willing to trade-off days alive for a better QoL [59]. The spectrum and intensity of the symptom burden of those with severe HF are shown in Table 2. We shall address some of these symptoms in detail.

Dyspnea Dyspnea is common in HF and may vary in duration and intensity in response to exertion, emotion, or environmental triggers. Those with advanced chronic HF become breathless on minimal exertion such as those required of the activities of daily living (ADL). Breathlessness as described by patients with a variety of advanced disease states, including $\mathrm{HF}$, may also be characterized as acute, episodic, or continuous [60]. Based on the Charité Emergency Medicine (CHARITEM) study in Germany, acute dyspnea was the main complaint in $65.1 \%$ of those requiring emergency hospital admission with HF [61], and although pulmonary edema as assessed by clinical examination or lung ultrasound is
Table 2 Refractory symptoms in severe heart failure

\begin{tabular}{lll}
\hline Symptom & Prevalence (\%) & $\begin{array}{l}\text { Intensity } \\
(0-10)\end{array}$ \\
\hline Malaise & 100 & 5.1 \\
Dyspnea & 92 & 5.3 \\
Tiredness & 92 & 5.6 \\
Pain & 60 & 2.8 \\
Anorexia & 82 & 3.7 \\
Nausea & 28 & 1.0 \\
Anxiety & 68 & 3.2 \\
Depression & 66 & 3.0 \\
Drowsiness & 6 & 3.6 \\
\hline
\end{tabular}

Spectrum and intensity (mean ESAS score) of refractory symptomsNHYA III/IV HF

NYHA, New York Heart Association; ESAS, Edmonton Symptom Assessment System (modified from O’Leary et al. [20])

common in such patients, breathlessness at rest may not be their dominant symptom. In a retrospective review of 311 acute admissions to an academic HF service in England, only $42 \%$ reported breathlessness at rest, the others becoming breathless on slight exertion similar to ambulatory patients with severe disease living in the community [62]. At presentation with acute HF, the severity of dyspnea correlates with the degree of congestion and requires the use of parenteral loop diuretic therapy with careful monitoring of renal function. Those with a history of paroxysmal nocturnal dyspnea or orthopnea, when acute pulmonary edema is more common, require to be nursed in a supported upright or semi-upright (Fowler) position. Opiates have demonstrable efficacy in those with chronic breathlessness, but most data are based on patients with COPD. However, the recently published phase III BreatheMOR-HF RCT of the daily administration of a $20 \mathrm{mg}$ modified release morphine preparation shows benefit in those with chronic HF [63]. Opiates may also alleviate the anxiety and distress associated with acute breathlessness; however, the safety of the previously widely endorsed use of short-term intravenous opiates in those with acute pulmonary edema has been questioned of late [64], and the outcome of the ongoing MIdazolam versus MOrphine in Acute Pulmonary Edema (MIMO) Trial (ClinicalTrials.gov Identifier: NCT02856698) remains to be determined. In those with demonstrable hypoxemia, supplemental oxygen therapy is indicated, the need for non-invasive or mechanical ventilation being considered if this persists or there is evidence of respiratory acidosis. It is important to ensure that such treatment escalation is consistent with patient preferences for care.

Fatigue Alongside breathlessness, fatigue is an almost universal symptom in HF, this being documented in $95 \%$ of those affected [65]. Fatigue was specifically recorded in $39 \%$ of 
patients presenting with incident HF and cited as their worst symptom by $32 \%$ of 371 patients admitted with ADCHF, this responding less well to treatment than dyspnea [66, 67]. The background is likely multifactorial, and a variety of pathophysiologic mechanisms may contribute including low cardiac output with reduced tissue perfusion, structural and metabolic abnormalities of the myocardium and skeletal muscle, and autonomic dysfunction $[68,69]$. Patients with fatigue are usually older, female, and with multiple comorbidities including depression and frailty-cachexia syndromes. There is a particular association with HF hospitalization, but fatigue per se is not a strong predictor of cardiovascular or all-cause mortality $[65,67]$. However, this relatively refractory symptom impacts patients' functional capacity and psychosocial well-being, often resulting in them becoming more dependent on others to fulfill required ADLs.

Pain Cicely Saunders was the first to conceptualize the theory of total pain as comprising physical, spiritual, psychological, and social constituents, and this has been proposed as a model relevant to those with advanced HF [70]. While the impact of pain is often unrecognized in this condition, the multi-site PAIN-HF study conducted across the US demonstrated that $84 \%$ of ambulatory patients with severe chronic HF experienced significant pain affecting QoL [71]. A comparable prevalence of pain at $85 \%$ was reported for acute HF patients assessed during hospitalization in Norway [72]. In both these studies, most patients exhibited HFrEF and pain may be more common in ADCHF patients with this phenotype [73]. This symptom appears to be relatively refractory, and $69 \%$ of 169 acute HF inpatients in Canada still complained of moderate to severe pain when assessed at the point of hospital discharge, this continuing and of similar intensity in $41 \%$ when reassessed 6 weeks later [74]. Pain experienced by HF patients is not usually cardiogenic, and a previous review has comprehensively described the pathophysiologic mechanisms and outlined treatment strategies [75]. As with breathlessness, opiates appear to be relatively effective and non-steroidal antiinflammatory preparations are generally contraindicated.

\section{Psychological and Psychiatric Care}

Importantly, symptoms do not occur in isolation but rather in clusters, and there is often an interdependency between those of somatic and psychologic origin [76]. Anxiety may heighten the perception of breathlessness, and as outlined above, fatigue may be associated with depression.

Anxiety The reported prevalence of anxiety in HF varies due to disparities in methods of assessment, but a recent metaanalysis reported a random effects pooled prevalence of $13 \%$ for a formal anxiety disorder, $29 \%$ for probable clinically significant anxiety, and $56 \%$ for heightened symptoms of anxiety [77]. Based on the Hospital Anxiety Depression Scale, moderate to severe anxiety was documented in $18 \%$ of patients hospitalized with HF [78], this correlating with increased rates of rehospitalization and mortality, such outcomes less frequently reported for those with chronic HF [79].

Depression Clinically significant depression affects about $22 \%$ of HF patients, and unsurprisingly, prevalence varies with functional limitation, documented as $11 \%$ and $42 \%$ for New York Heart Association classes I and IV respectively [80]. Compared to anxiety, depression has been more consistently linked to poorer survivorship, and associated with a twofold increase in mortality for the general HF population. However, for those with acute HF, the risk may be greater. In the OPERA-HF observational study of HF admissions, 15\% of 242 patients with moderate to severe depression had a near fivefold increase in all-cause mortality by 12 months postdischarge [81].

The background to these adverse outcomes for anxiety and depression is unclear and may relate to both altered biologic mechanisms involving increased inflammation and platelet aggregability with endothelial dysfunction, or the adoption of adverse health behaviors such as poor medication adherence or physical inactivity [82•]. Treating anxiety and depression may be based on psychotherapeutic, educational, or pharmacologic approaches. For all treatment modes, evidence has largely evolved from those with chronic HF. Cognitive behavioral therapy has shown some benefits for both anxiety and depression. Medication in the form of selective serotonin reuptake inhibitors has generally been regarded as first-line therapy based on their relative safety and effectiveness in noncardiac patients, but results vary in those with HF. Two RCTs examining the effects of sertraline (SADHART-CHF) and escitalopram (MOOD-HF) showed responses equivalent to placebo $[83,84]$. Other drugs such as tricyclic antidepressants may be pro-arrhythmic, and venlafaxine and duloxetine may worsen HF, and are best avoided. The $\alpha-2$ antagonist mirtazapine is commonly prescribed for depression; however, the efficacy and safety of this drug has not been systematically evaluated in the HF population. Accessing psychiatric expertise through the MDT process may facilitate optimal treatment and improve clinical outlook.

Cognitive Impairment Disorders of cognition are common in those with HF and may occur as both acute and chronic progressive forms. Delirium, an acute confusional state evident as inattention and global cognitive dysfunction, has been reported in $17-35 \%$ of patients admitted with de novo AHF or $\mathrm{ADCHF}$, and associated with poor outcomes in worsening HF during hospitalization, increased length of stay and readmission rates, and greater short and long-term cardiovascular and all-cause mortality $[85,86]$. Delirium may be directly 
related to acute HF in hypoxia or hypotension-related cerebral hypoperfusion. As with patients admitted with other acute medical conditions, delirium may be triggered by exposure to unfamiliar, apparently threatening surroundings, compounded by disruption of sleep architecture. Management includes reassurance and reorientation in space and time. Significant agitation may respond to haloperidol, with monitoring for QT prolongation, or the use of other anti-psychotic agents such as risperidone. Benzodiazepines may be particularly helpful in delirium due to alcohol withdrawal.

Chronic cognitive impairment is estimated to affect about $40 \%$ of HF patients, irrespective of ejection fraction phenotype [87]. This can vary in severity across several domains including attention, memory, speech and language processing, learning, and executive function. A previous study found that $80 \%$ of 774 patients admitted with ADCHF were impaired in at least one domain, this predominantly involving memory, processing speed, and executive function [88]. Depressed patients were twice as likely to be impaired in all three of these domains. No causal link has been established with HF although cerebral hypoperfusion and occult cardioembolic disease have been proposed as potential mechanisms. Impaired cognition may also result from specific forms of dementia across a range of pathophysiologic processes, these conditions simply coexisting in the typically affected elderly population. To date there is no evidence to suggest that any drugs within GDMT for HF directly affect cognition. However, downregulation of the enzyme neprilysin increases cerebral deposition of amyloid- $\beta$ protein, a hallmark of Alzheimer's disease. Following the positive outcomes of the PARAGON-HF study in those with HFrEF, the angiotensin receptor-neprilysin inhibitor sacubitril/valsartan is increasingly prescribed. A retrospective analysis of the PARAGON-HF study group revealed no excess of dementia compared to other HF trial populations [89], but a prospective study is currently underway to assess the effects of neprilysin inhibition on cognitive function in those with chronic HF (NCT02884206). The EAPC has issued a white paper describing optimal PC for those with dementia [90]. The high prevalence of cognitive impairment in chronic HF suggests that enactment of advance directives might be useful in those at risk of losing capacity, but such constructs have been poorly espoused by this population, being documented in only $13 \%$ of those admitted with ADCHF [91].

\section{Social Care}

Socioeconomic disadvantage is widely acknowledged as contributing to the risk profile for cardiovascular disease, often evident in a final common pathway as HF. A recent American Heart Association (AHA) Scientific Statement specifically addressing the social determinants of health (SDOH) for this clinical cohort reiterated the WHO definition of these as "the circumstances in which people are born, grow up, live, work and age......and the systems put in place to offer health care and services to a community" [92••]. Against this multifaceted backdrop, people with HF who are of non-white race or otherwise marginalized, those with modest educational attainment, economic instability, poor living conditions, or lacking in social support or access to effective health care structures, face worse outcomes with this condition. This vulnerability was evident in a study of 690 Medicare beneficiaries > 65 years discharged alive after HF hospitalization who showed a close to threefold increase in 90-day mortality if they were exposed to only one of nine possible $\mathrm{SDOH}$ as defined in the REGARDS (Reasons for Geographic and Racial Differences in Stroke) study, even when patients discharged to hospice were excluded [93]. The AHA statement explicitly highlighted poor access to PC in such disadvantaged populations, and a systematic review has demonstrated that people living in high-income countries with low socioeconomic standing experience poorer quality end-of-life care with increased use of acute medical services in the 3month period before death, higher rates of death in hospital, and lesser involvement of specialist PC services during their last year of life [94].

Socioeconomic deficits affect the well-being of both HF patients and their informal carers, the latter often sharing a common heritage, lived environment, and also mediating health behaviors. There is also a gendering issue in that for men, a disproportionate amount of that caring burden is assumed by women, whereas older women, not infrequently affected by HF, may be bereft of spousal support. Clearly such risk elements are multifactorial, inter-related, and cumulative, and an intersectional approach has recently been proposed as appropriate to the investigation of HF patient-carer dyads [95]. Sociodemographic subsets such as single person households, minority language groups, and those living in rural areas may be particularly exposed. Some of the factors underlying $\mathrm{SDOH}$ are not modifiable, but greater social work involvement and multiagency supportive care beyond the biomedical paradigm of clinical PC, might be beneficial in addressing the unmet needs of these vulnerable populations.

\section{Spiritual, Religious, and Existential Support}

Spirituality is intrinsic to human nature, and supporting this has been proposed as central to the holistic bio-psychosocialspiritual model required of PC for those with significant illness or near the end of life [96]. It is important to emphasize that spirituality is not synonymous with organized religion or religiosity, but rather a broader concept involving a sense of life's purpose, meaning, connectedness, and transcendence to a higher power, nature, or humanity in toto. 
Following the development of an international consensus in 2014 , the EAPC defined spirituality as:

\section{The dynamic dimension of human life that relates to the way persons (individual and community) experience, express and / or seek meaning, purpose and transcen- dence, and the way they connect to the moment, to self, to others, to nature, to the significant and / or the sacred.}

To some extent, the above definition also encompasses existential well-being, the means by which people adjust to self, their community and environment, their interconnectedness with others, and their degree of reconciliation with earlier life events [97]. Recent work emphasizes the inherent uniqueness of the spiritual needs of patient/carer dyads, and also their willingness to engage with professionals to foster resilience and coping skills arising from spiritual support [98]. For those active in religious observance, this might be provided through chaplaincy services, with secular pastoral care available to others. This study also suggested that patients and families would prefer all healthcare professionals to contribute to this element of care at some level, at least in engaging in empathetic patient-centered communication, and being what has been described as a "compassionate presence" [99]. Yet it is widely acknowledged that clinicians often feel illequipped to explore and respond to spiritual issues, highlighting the need for professional education in this field.

Spiritual well-being of HF patients tends to follow the vagaries of their physical and psychological health along the disease trajectory, and this has been specifically linked to acute hospitalization [100]. While there has been increased interest in addressing the spiritual needs of those with HF, and various psychotherapeutic approaches including life review have been proposed, a particularly effective model of support is yet to be elaborated [101].

\section{Culturally Competent Care Provision}

National populations across the world are increasingly culturally diverse, this pluralism resulting from escalating global migration, the United Nations estimating that in 2015, more than 244 million people were living in a country other than that of their birth [102]. As clinicians we interact with patients and families who align with many cultures, culture being defined as "a system of shared ideas and meanings that underlie, influence and structure the ways in which people think and act in practical situations" [103]. Culture has a degree of granularity, and even across ethnocultural groups and within families, attitudes of individuals vary depending on how deeply rooted they are within their own culture, or their degree of acculturation with the dominant indigenous population within which they are embedded. Culture influences a person's worldview and affects responses to significant illness, some searching for a sense of purpose in suffering coupled to their spiritual connection or faith tradition, this sometimes shaping treatment preferences and engagement with care processes and ultimately determining outcomes [104]. Open awareness of dying by those facing the inexorable progress of diseases such as $\mathrm{HF}$ is a philosophy supported by PC professionals, allowing people to come to terms with their situation, and as a means of developing care plans to better ensure a good death. However, such truth telling policies have emerged in predominantly Anglophone regions, and run counter to the sociocultural norms of other societies wherein death taboos exist in the belief that even discussing the dying process or imminent death will hasten that end. Preferences for non-disclosure may affect patient autonomy and undermine the principle of shared decision making. In some cultures, patients prefer to rely on collective decisions made within families, or to defer treatment choices to their physicians whom they regard as vested with epistemic authority. In such situations it is important that clinicians are aware of their own biases which might influence judgment calls. While the subtleties required of sensitive communication might be lost in translation if professionals and patient/carer dyads do not share a common first language, calibrating such conversations with the help of interpreters might engender trust. This may facilitate consensus building in taking forward clinically appropriate decisions regarding initiation of PC, resuscitation policies, and ACP for HF management. Health care providers need to have processes in place to support the range of cultural perspectives and needs specific to their local communities with cardiovascular disease [105•].

\section{Care Near the End of Life}

Given the stuttering nature of the HF disease - death trajectory, recognition of the dying phase is challenging. A recent study of clinical decision making at the end of life, which included 81 acute HF inpatients, suggested that such discernment was often instinctive and cloaked with uncertainty [106]. Indeed, acknowledging uncertainty may itself be a useful premise on which to base further discussion with the patient and family, and to re-explore their values, goals, and preferences for treatment options in the setting of progressive clinical deterioration [107]. A reluctance of professionals to broach issues of death and dying is understandable, but evidence suggests that recently hospitalized HF patients frequently reflect on these matters and are fearful about dying in hospital which is the usual outcome [108, 109]. Many patients would prefer to die in familiar surroundings at home [110], and while achieving the preferred place of death is regarded as a key performance indicator of good quality end-of-life care, it is important to ensure that such patients are properly supported. In a recent 
retrospective study of $3981 \mathrm{HF}$ decedents from the Swedish Register of Palliative Care, of those dying at home or in nursing homes, $17.2 \%$ died alone, with no family or healthcare professionals in attendance [36].

Hospice in the form of a dedicated palliative care facility is underutilized in HF. In the US, "hospice" care is available at home through the Medicare Hospice Benefit Program for patients certified as having a likely life expectancy of $\leq 6$ months, and who choose to forgo curative therapy. It has been estimated that close to one-third of American HF patients have subscribed to this scheme by the time of death [111]. Enrolment tends to occur late in the course of the disease but is associated with reduced use of acute medical services.

Optimizing care at the end of life requires reexamination of the utility of previously prescribed medication and any implanted device therapy, the benefits or burdens of invasive measures to support hydration or nutrition, and the appropriateness of intensive care. For those distressed with multiple symptoms, anticipatory prescribing of all potentially necessary medication should be considered [112•]. Comprehensive GDMT for HF entails polypharmacy, but much of this helps maintain ventricular function, and withdrawal risks symptomatic deterioration. However, some long-prescribed drugs such as statins may be rendered superfluous in this disease phase and deprescription may be reasonable [113]. Similarly, the efficacy of anticoagulation may approach clinical equipoise depending on the clinical indication, although changing from warfarin to a direct anticoagulant may reduce the treatment burden. Patients with advanced HF increasingly receive continuous inotropic therapy as a form of palliation [114]. While inotropes can be administered at home, this may be impractical for some, obliging them to stay in hospital, and this therapy may be disallowed in those transitioning to hospice care.

The use of implantable cardioverter-defibrillator (ICD) therapy for the primary or secondary prevention of sudden death as directed by clinical guidelines is rising exponentially. While there is unequivocal evidence of benefit in device-eligible patients, there are numerous reports of patients receiving distressing and purposeless shocks close to the end of life [115]. The possibility of later device deactivation should be introduced as part of the consent process prior to the primary implantation when bundling with value-based ACP may be advantageous [116], revisiting this issue along the disease trajectory after crises, or when considering generator replacement. Society guidelines provide protocols for ethically appropriate ICD deactivation, and it is important to ensure the ready availability of trained staff and equipment to facilitate this process [117]. Similarly, MCS in the use of durable ventricular assist devices (VADs) as a bridge to decision making, recovery or transplantation, or as destination therapy, is becoming more common [118]. Since 2013, the Centers for Medicare and Medicaid Services in the US have mandated PC involvement in this process, this requirement driving a broader inter-disciplinary collaboration between cardiology, cardiac surgery, and PC [119, 120]. Palliative care supports preparedness planning for HF patients and families considering MCS, as well as supporting them towards the end of life, or if active discontinuation of VAD therapy is required following major device-related complications [121]. Similar issues arise if ECMO support for acute HF is being withdrawn, although there is less experience with that technology at this time [122]. ECMO is often employed in a time-limited emergent fashion, and families may have little concept of the nature or implications of this form of treatment, underscoring the need for sensitivity and good communication.

\section{Ethical and Legal Constructs Relevant to Care}

The ethical principles of autonomy, beneficence, non-maleficence, and justice are clearly relevant to those with presenting with acute HF, particularly late in the disease course. Autonomy mandates that the competent patient be sufficiently informed of the nature of their condition to enable them to accept or refuse proposed treatment elements consistent with their preferences and values, this shared decision-making policy endorsed by the AHA [15]. If HF patients lose capacity, informal carers often assume a surrogate role as decision makers. Disagreements may arise between families and health care professionals on treatment policies when the involvement of a clinical ethicist may be useful, and these individuals may also help formulate a consensus in defining ceilings of care and the withdrawal of therapies now considered non-beneficial. The benefits of $\mathrm{ACP}$ or any previous statements by the patient are clearly relevant here, their status subject to the nature of the instrument enacted and local legislation. Policies on DNACPR also fall within this compass, and it is important to note that there is much variation across jurisdictions in the chain of responsibility for such orders and their legality, often influenced by societal and cultural factors.

In compiling this paper, we take a neutral stance and do not offer guidance on assisted suicide or euthanasia, but it should be noted that physician-assisted dying is legal in many countries and territories internationally.

\section{Conclusion}

As with chronic HF, providing PC to those with acute HF presents challenges and opportunities. Organizational barriers might come into play in that some systems of care 
may not sanction inclusion of PC within the HF care bundle, or the necessary workforce may be unavailable. More commonly, there is still a failure to appreciate that the concurrent provision of PC alongside GDMT aimed at life prolongation is not incongruous. For many patients admitted with acute HF, some of whom will die in hospital, there is often a tension in reconciling the "treatment imperative" and the "ethical imperative" in the need to provide comfort care. This dilemma is evident in considering the clinical characteristics behind the I-NEEDHELP mnemonic [123], proposed as an aide-mémoire describing those potentially requiring advanced HF therapies, but which are no less applicable as markers of PC need. Embedding PC within a HF MDT from the time of diagnosis avoids silo working, needs assessment undertaken as an iterative process along the capricious disease trajectory enabling incremental PC involvement during disease progression, with formulation of appropriate treatment escalation and withdrawal policies as patients decline towards the end of life. Close to death, it is important that HF professionals trusted by patients and families remain engaged, avoiding a perception of abandonment.

Themes emerging from a recent review examining the barriers and facilitators of a "good death" in HF [124] included the following: (a) effective communication between patients/families/healthcare providers; (b) good clinical navigation through the terminal phase and dying process; (c) the avoidance of futile invasive interventions; (d) good symptom control; (e) timely access to specialist PC, including bereavement care; and (f) achieving the preferred place of care and death. The domains included in the National Consensus Project Clinical Practice Guidelines provide useful benchmarks of the quality of PC required for those with acute and chronic HF, up to and including that final transition.

\section{Compliance with Ethical Standards}

Conflict of Interest JMB is a member of the ESC Heart Failure Association Palliative Care Task Force.

Human and Animal Rights and Informed Consent The authors conducted no studies with animals or human subjects related to this review.

Open Access This article is licensed under a Creative Commons Attribution 4.0 International License, which permits use, sharing, adaptation, distribution and reproduction in any medium or format, as long as you give appropriate credit to the original author(s) and the source, provide a link to the Creative Commons licence, and indicate if changes were made. The images or other third party material in this article are included in the article's Creative Commons licence, unless indicated otherwise in a credit line to the material. If material is not included in the article's Creative Commons licence and your intended use is not permitted by statutory regulation or exceeds the permitted use, you will need to obtain permission directly from the copyright holder. To view a copy of this licence, visit http://creativecommons.org/licenses/by/4.0/.

\section{References}

Papers of particular interest, published recently, have been highlighted as:

- Of importance

• Of major importance

1. Bleumink GS, Knetsch AM, Sturkenboom MC, Straus SM, Hofman A, Deckers JW, et al. Quantifying the heart failure epidemic: prevalence, incidence rate, lifetime risk and prognosis of heart failure. The Rotterdam study. Eur Heart J. 2004;25(18): 1614-9. https://doi.org/10.1016/j.ehj.2004.06.038.

2. Heidenreich PA, Albert NM, Allen LA, Bluemke DA, Butler J, Fonarow GC, et al. Forecasting the impact of heart failure in the United States: a policy statement from the American Heart Association. Circ Heart Fail. 2013;6:606-19. https://doi.org/10. 1161/HHF.0b013e318291329a.

3. Conrad N, Judge A, Tran J, Mohseni H, Hedgecott D, Crespillo AP, et al. Temporal trends and patterns in heart failure incidence: a population-based study of 4 million individuals. Lancet. 2018;391(10120):572-80. https://doi.org/10.1016/S01406736(17)32520-5.

4. Lloyd-Jones DM, Larson MG, Leip EP, Beiser A, D'Agostino RB, Kannel WB, et al. Lifetime risk for developing congestive heart failure: the Framingham Heart Study. Circulation. 2002;106(24): 3068-72. https://doi.org/10.1161/01.cir.0000039105.49749.6f.

5. Cook C, Cole G, Asaria P, Jabbour R, Francis DP. The annual global economic burden of heart failure. Int $\mathrm{J}$ Cardiol. 2014;171(3):368-76. https://doi.org/10.1016/j.ijcard.2013.12. 028.

6. Ponikowski P, Voors AA, Anker SD, Bueno H, Cleland JGF, Coats AJS, et al. 2016 ESC guidelines for the diagnosis and treatment of acute and chronic heart failure: the Task Force for the diagnosis and treatment of acute and chronic heart failure of the European Society of Cardiology (ESC) developed with the special contribution of the Heart Failure Association (HFA) of the ESC. Eur Heart J. 2016;37:2129-200. https://doi.org/10.1093/eurheartj/ ehw128.

7. Greene SJ, Hernandez AF, Dunning A, Ambrosy AP, Armstrong $\mathrm{PW}$, Butler J, et al. Hospitalization for recently diagnosed versus worsening chronic heart failure: from the ASCEND-HF trial. J Am Coll Cardiol. 2017;69(25):3029-39. https://doi.org/10.1016/ j.jacc.2017.04.043.

8. Nielsen OW, Valeur N, Sajadieh A, Fabricius-Bjerre A, Carlsen CM, Kober L. Echocardiographic subtypes of heart failure in consecutive hospitalised patients with dyspnoea. Open Heart. 2019;6(1):e000928. https://doi.org/10.1136/openhrt-2018000928.

9. Yancy CW, Jessup M, Bozkurt B, Butler J, Casey DE Jr, Drazner $\mathrm{MH}$, et al. $2013 \mathrm{ACCF} / \mathrm{AHA}$ guideline for the management of heart failure: a report of the American College of Cardiology Foundation/American Heart Association Task Force on Practice Guidelines. J Am Coll Cardiol. 2013;62(16):e147-239. https:// doi.org/10.1016/j.jacc.2013.05.019.

10. Hollenberg SM, Warner Stevenson L, Ahmad T, Amin VJ, Bozkurt B, Butler J, et al. 2019 ACC expert consensus decision pathway on risk assessment, management, and clinical trajectory of patients hospitalized with heart failure: a report of the American College of Cardiology Solution set Oversight Committee. J Am Coll Cardiol. 2019;74(15):1966-2011. https://doi.org/10.1016/j. jacc.2019.08.001 The above paper provides an excellent summary of practical in-patient HF management. 
11. Clark AL, Cherif M, McDonagh TA, Squire IB. In-hospital worsening heart failure: a clinically relevant endpoint? ESC Heart Fail. 2018;5(1):9-18. https://doi.org/10.1002/ehf2.12195.

12. National Heart Failure Audit 2019 Summary report. Healthcare Quality Improvement Partnership, 2019. https://www.hqip.org. uk/wp-content/uploads/2019/09/Ref-129-Cardiac-Heart-FailureSummary-Report-2019-FINAL.pdf. Accessed 24 June 2020.

13. Nieminen MS, Brutsaert D, Dickstein K, Drexler H, Follath F, Harjola VP, et al. EuroHeart Failure Survey II (EHFS II): a survey on hospitalized acute heart failure patients: description of population. Eur Heart J. 2006;27(22):2725-36. https://doi.org/10.1093/ eurheartj/ehl193.

14. Cleland JG, McDonagh T, Rigby AS, Yassin A, Whittaker T, Dargie HJ, et al. The national heart failure audit for England and Wales 2008-2009. Heart. 2011;97(11):876-86. https://doi.org/10. 1136/hrt.2010.209171.

15. Allen LA, Stevenson LW, Grady KL, Goldstein NE, Matlock DD, Arnold RM, et al. Decision making in advanced heart failure: a scientific statement from the American Heart Association. Circulation. 2012;125:1928-52. https://doi.org/10.1161/CIR. 0b013e31824f2173.

16. Shen L, Jhund PS, Petrie MC, Claggett BL, Barlera S, Cleland JGF, et al. Declining risk of sudden death in heart failure. N Engl J Med. 2017;377(1):41-51. https://doi.org/10.1056/ NEJMoa1609758.

17. Pokorney SD, Al-Khatib SM, Sun JL, Schulte P, O'Connor CM, Teerlink JR, et al. Sudden cardiac death after acute heart failure hospital admission: insights from ASCEND-HF. Eur J Heart Fail. 2018;20(3):525-32. https://doi.org/10.1002/ejhf.1078.

18. Meijers WC, Maglione M, Bakker SJL, Oberhuber R, Kieneker LM, de Jong S, et al. Heart failure stimulates tumor growth by circulating factors. Circulation. 2018;138(7):678-91. https://doi. org/10.1161/CIRCULATIONAHA.117.030816.

19. Sepúlveda C, Marlin A, Yoshida T, Ullrich A. Palliative care: the World Health Organization's global perspective. J Pain Symptom Manag. 2002;24(2):91-6. https://doi.org/10.1016/s08853924(02)00440-2.

20. O'Leary N, Murphy NF, O'Loughlin C, Tiernan E, McDonald K. A comparative study of the palliative care needs of heart failure and cancer patients. Eur J Heart Fail. 2009;11(4):406-12. https:// doi.org/10.1093/eurjhf/hfp007.

21. Moens K, Higginson IJ, Harding R, EURO IMPACT. Are there differences in the prevalence of palliative care-related problems in people living with advanced cancer and eight non-cancer conditions? A systematic review. J Pain Symptom Manag. 2014;48(4): 660-77. https://doi.org/10.1016/j.jpainsymman.2013.11.009.

22. McKelvie RS, Moe GW, Cheung A, Costigan J, Ducharme A, Estrella-Holder E, et al. The 2011 Canadian Cardiovascular Society heart failure management guidelines update: focus on sleep apnea, renal dysfunction, mechanical circulatory support, and palliative care. Can J Cardiol. 2011;27(3):319-38. https:// doi.org/10.1016/j.cjca.2011.03.011.

23.• Hill L, Geller TP, Baruah R, Beattie JM, Boyne J, De Stoutz N, et al. Integration of a palliative approach into heart failure care: a European Society of Cardiology Heart Failure Association position paper. Eur J Heart Fail. 2020. https://doi.org/10.1002/ejhf. 1994 A highly relevant position paper on integrating PC for HF from the ESC HFA.

24.• Sobanski PZ, Alt-Epping B, Currow DC, Goodlin SJ, Grodzicki $\mathrm{T}$, Hogg K, et al. Palliative care for people living with heart failure: European Association for Palliative Care Task Force expert position statement. Cardiovasc Res. 2020;116(1):12-27. https://doi. org/10.1093/cvr/cvz200 A recently published position statement from the EAPC on PC provision for HF.

25. Gelfman LP, Kavalieratos D, Teuteberg WG, Lala A, Goldstein NE. Primary palliative care for heart failure: what is it? How do we implement it? Heart Fail Rev. 2017;22(5):611-20. https://doi.org/ 10.1007/s10741-017-9604-9.

26.• Lewin WH, Cheung W, Horvath AN, Haberman S, Patel A, Sullivan D. Supportive cardiology: moving palliative care upstream for patients living with advanced heart failure. J Palliat Med. 2017;20(10):1112-9. https://doi.org/10.1089/jpm.2016. 0317 A cogent argument supporting the applicability of PC throughout the $\mathrm{HF}$ disease trajectory.

27. Ferrell BR, Twaddle ML, Melnick A, Meier DE. National Consensus Project Clinical Practice Guidelines for quality palliative care guidelines, 4th edition. J Palliat Med. 2018;21(12):1684 9. https://doi.org/10.1089/jpm.2018.0431.

28. Low J, Pattenden J, Candy B, Beattie JM, Jones L. Palliative care in advanced heart failure: an international review of the perspectives of recipients and health professionals on care provision. $\mathrm{J}$ Card Fail. 2011;17:231-52. https://doi.org/10.1016/j.cardfail. 2010.10.003.

29. Rogers M, Heitner R. Latest trends and insights in hospital palliative care 2019. Center to advance palliative care. 2019. Available at https://www.capc.org/documents/695/ Accessed 21 July 2020.

30. Arias-Casais N, Garralda E, Rhee J, De Lima L, Pons Izquierdo J, Clark D, et al. EAPC atlas of palliative care in Europe 2019. Vilvoorde: EAPC Press; 2019.

31. Selman L, Brighton L, Harding R. Palliative and supportive care needs of heart failure patients in Africa: a review of recent developments. Curr Opin Support Palliat Care. 2015;9(1):20-5. https:// doi.org/10.1097/SPC.0000000000000107.

32. Widera E, Pantilat SZ. Hospitalization as an opportunity to integrate palliative care in heart failure management. Curr Opin Support Palliat Care. 2009;3(4):247-51. https://doi.org/10.1097/ SPC.0b013e3283325024.

33. Alqahtani F, Balla S, Almustafa A, Sokos G, Alkhouli M. Utilization of palliative care in patients hospitalized with heart failure: a contemporary national perspective. Clin Cardiol. 2019;42(1):136-42. https://doi.org/10.1002/clc.23119.

34. Wiskar KJ, Celi LA, McDermid RC, Walley KR, Russell JA, Boyd $\mathrm{JH}$, et al. Patterns of palliative care referral in patients admitted with heart failure requiring mechanical ventilation. Am J Hosp Palliat Care. 2018;35(4):620-6. https://doi.org/10.1177/ 1049909117727455

35. Cleland J, Dargie H, Hardman S, McDonagh T, Mitchell P. National heart failure audit: April 2011- March 2012. London: National Institute for Cardiovascular Outcomes Research; 2012.

36. Årestedt K, Alvariza A, Boman K, Öhlén J, Goliath I, Håkanson $\mathrm{C}$, et al. Symptom relief and palliative care during the last week of life among patients with heart failure: a national register study. $\mathrm{J}$ Palliat Med. 2018;21(3):361-7. https://doi.org/10.1089/jpm.2017. 0125 .

37. Warraich HJ, Wolf SP, Mentz RJ, Rogers JG, Samsa G, Kamal $\mathrm{AH}$. Characteristics and trends among patients with cardiovascular disease referred to palliative care. JAMA Netw Open. 2019;2(5): e192375. https://doi.org/10.1001/jamanetworkopen.2019.2375.

38. Stocker R, Close H, Hancock H, Hungin APS. Should heart failure be regarded as a terminal illness requiring palliative care? A study of heart failure patients', carers' and clinicians' understanding of heart failure prognosis and its management. BMJ Support Palliat Care. 2017;7(4):464-9. https://doi.org/10.1136/bmjspcare2016-001286.

39. Abraham WT, Fonarow GC, Albert NM, Stough WG, Gheorghiade M, Greenberg BH, et al. Predictors of in-hospital mortality in patients hospitalized for heart failure: insights from the Organized Program to Initiate Lifesaving Treatment in Hospitalized Patients with Heart Failure (OPTIMIZE-HF). J Am Coll Cardiol. 2008;52:347-56. https://doi.org/10.1016/j.jacc. 2008.04.028. 
40. Straw S, Byrom R, Gierula J, Paton MF, Koshy A, Cubbon R, et al. Predicting one-year mortality in heart failure using the 'Surprise Question': a prospective pilot study. Eur J Heart Fail. 2019;21(2):227-34. https://doi.org/10.1002/ejhf.1353.

41. Hogg KJ, Jenkins SM. Prognostication or identification of palliative needs in advanced heart failure: where should the focus lie? Heart. 2012;98(7):523-4. https://doi.org/10.1136/heartjnl-201230175.

42. Bruera E, Kuehn N, Miller MJ, Selmser P, Macmillan K. The Edmonton Symptom Assessment System (ESAS): a simple method for the assessment of palliative care patients. J Palliat Care. 1991;7(2):6-9.

43. Lyons KD, Bakitas M, Hegel MT, Hanscom B, Hull J, Ahles TA. Reliability and validity of the Functional Assessment of Chronic IllnessTherapy-Palliative care (FACIT-Pal) scale. J Pain Symptom Manag. 2009;37(1):23-32. https://doi.org/10.1016/j. jpainsymman.2007.12.015.

44. Kane PM, Daveson BA, Ryan K, Ellis-Smith CI, Mahon NG, McAdam B, et al. Feasibility and acceptability of a patientreported outcome intervention in chronic heart failure. BMJ Support Palliat Care. 2017;7(4):470-9. https://doi.org/10.1136/ bmjspcare-2017-001355 A study supporting the use of IPOS in assessing $\mathrm{PC}$ needs in $\mathrm{HF}$.

45. Waller A, Girgis A, Davidson PM, Newton PJ, Lecathelinais C, Macdonald PS, et al. Facilitating needs-based support and palliative care for people with chronic heart failure: preliminary evidence for the acceptability, interrater reliability, and validity of a needs assessment tool. J Pain Symptom Manag. 2013;45:912-25. https://doi.org/10.1016/j.jpainsymman.2012.05.009 Description of a HF-specific instrument to assess PC needs.

46. Campbell RT, Petrie MC, Jackson CE, Jhund PS, Wright A, Gardner RS, et al. Which patients with heart failure should receive specialist palliative care? Eur J Heart Fail. 2018;20(9):1338-47. https://doi.org/10.1002/ejhf.1240.

47. Roch C, Palzer J, Zetzl T, Störk S, Frantz S, van Oorschot B. Utility of the integrated palliative care outcome scale (IPOS): a cross-sectional study in hospitalised patients with heart failure. Eur J Cardiovasc Nurs. 2020:147451512091938. https://doi.org/ 10.1177/1474515120919386.

48. Diop MS, Rudolph JL, Zimmerman KM, Richter MA, Skarf LM. Palliative care interventions for patients with heart failure: a systematic review and meta-analysis. J Palliat Med. 2017;20(1):84 92. https://doi.org/10.1089/jpm.2016.0330 A methodical review of HF PC interventions.

49.• Sahlollbey N, Lee CKL, Shirin A, Joseph P. The impact of palliative care on clinical and patient-centred outcomes in patients with advanced heart failure: a systematic review of randomized controlled trials. Eur J Heart Fail. 2020. https://doi.org/10.1002/ejhf. 1783 An excellent meta-analysis of recent HF PC trials.

50. Sidebottom AC, Jorgenson A, Richards H, Kirven J, Sillah A. Inpatient palliative care for patients with acute heart failure: outcomes from a randomized trial. Palliat Med. 2015;18:134-42. https://doi.org/10.1089/jpm.2014.0192.

51. Hopp FP, Zalenski RJ, Waselewsky D, Burn J, Camp J, Welch $\mathrm{RD}$, et al. Results of a hospital-based palliative care intervention for patients with an acute exacerbation of chronic heart failure. $\mathrm{J}$ Card Fail. 2016;22(12):1033-6. https://doi.org/10.1016/j.cardfail. 2016.04.004.

52.• Rogers JG, Patel CB, Mentz RJ, Granger BB, Steinhauser KE, Fiuzat M, et al. Palliative care in heart failure: the PAL-HF randomized, controlled clinical trial. J Am Coll Cardiol. 2017;70(3): 331-41. https://doi.org/10.1016/j.jacc.2017.05.030 A landmark study describing an effective $\mathrm{PC}$ intervention for $\mathrm{HF}$ inpatients.

53. O'Riordan DL, Rathfon MA, Joseph DM, Hawgood J, Rabow MW, Dracup KA, et al. Feasibility of implementing a palliative care intervention for people with heart failure: Learnings from a pilot randomized clinical trial. J Palliat Med. 2019;22(12):1583-8. https://doi.org/10.1089/jpm.2018.0633.

54. Wong FK, Ng AY, Lee PH, Lam PT, Ng JS, Ng NH, et al. Effects of a transitional palliative care model on patients with end-stage heart failure: a randomised controlled trial. Heart. 2016;102(14): 1100-8. https://doi.org/10.1136/heartjnl-2015-308638.

55. O'Donnell AE, Schaefer KG, Stevenson LW, DeVoe K, Walsh K, Mehra MR, et al. Social worker-aided palliative care intervention in high-risk patients with heart failure (SWAP-HF): a pilot randomized clinical trial. JAMA Cardiol. 2018;3(6):516-9. https:// doi.org/10.1001/jamacardio.2018.0589.

56. Yorganci E, Evans CJ, Johnson H, Barclay S, Murtagh FE, Yi D, et al. Understanding usual care in randomised controlled trials of complex interventions: a multi-method approach. Palliat Med. 2020;34(5):667-79. https://doi.org/10.1177/0269216320905064.

57. Albert NM, Barnason S, Deswal A, Hernandez A, Kociol R, Lee E, et al. Transitions of care in heart failure: a scientific statement from the American Heart Association. Circ Heart Fail. 2015;8(2): 384-409. https://doi.org/10.1161/HHF.0000000000000006.

58. Riley JP, Beattie JM. Palliative care in heart failure: facts and numbers. ESC Heart Fail. 2017;4(2):81-7. https://doi.org/10. 1002/ehf2.12125 A comprehensive summary of PC for HF.

59. Stevenson LW, Hellkamp AS, Leier CV, Sopko G, Koelling T, Warnica JW, et al. Changing preferences for survival after hospitalization with advanced heart failure. J Am Coll Cardiol. 2008;52(21):1702-8. https://doi.org/10.1016/j.jacc.2008.08.028.

60. Simon ST, Higginson IJ, Benalia H, Gysels M, Murtagh FE, Spicer J, et al. Episodic and continuous breathlessness: a new categorization of breathlessness. J Pain Symptom Manag. 2013;45(6):1019-29. https://doi.org/10.1016/j.jpainsymman. 2012.06.008.

61. Searle J, Frick J, Möckel M. Acute heart failure facts and numbers: acute heart failure populations. ESC Heart Fail. 2016;3(2):65-70. https://oi.org/10.1002/ehf2.12092.

62. Shoaib A, Waleed M, Khan S, Raza A, Zuhair M, Kassianides X, et al. Breathlessness at rest is not the dominant presentation of patients admitted with heart failure. Eur J Heart Fail. 2014;16(12):1283-91. https://doi.org/10.1002/ejhf.153.

63. Johnson MJ, Cockayne S, Currow DC, Bell K, Hicks K, Fairhurst $\mathrm{C}$, et al. Oral modified release morphine for breathlessness in chronic heart failure: a randomized placebo-controlled trial. ESC Heart Fail. 2019;6(6):1149-60. https://doi.org/10.1002/ehf2. 12498.

64. Karim HMR, Esquinas A, Singha SK. Morphine therapy in acute heart failure is associated with increased mechanical ventilation and mortality: adverse dose-dependent effect or inevitable consequence? Int J Cardiol. 2019;297:92. https://doi.org/10.1016/j. ijcard.2019.07.072.

65. Perez-Moreno AC, Jhund PS, Macdonald MR, Petrie MC, Cleland JG, Böhm M, et al. Fatigue as a predictor of outcome in patients with heart failure: analysis of CORONA (Controlled Rosuvastatin Multinational Trial in Heart Failure). JACC Heart Fail. 2014;2(2):187-97. https://doi.org/10.1016/j.jchf.2014.01. 001.

66. Kato M, Stevenson LW, Palardy M, Campbell PM, May CW, Lakdawala NK, et al. The worst symptom as defined by patients during heart failure hospitalization: implications for response to therapy. J Card Fail. 2012;18(7):524-33. https://doi.org/10.1016/ j.cardfail.2012.04.012.

67. Williams BA. The clinical epidemiology of fatigue in newly diagnosed heart failure. BMC Cardiovasc Disord. 2017;17(1):122. https://doi.org/10.1186/s12872-017-0555-9.

68. Banerjee P. Heart failure: a story of damage, fatigue and injury? Open Heart. 2017;4(2):e000684. https://doi.org/10.1136/openhrt2017-000684. 
69. Evangelista LS, Moser DK, Westlake C, Pike N, Ter-Galstanyan A, Dracup K. Correlates of fatigue in patients with heart failure. Prog Cardiovasc Nurs. 2008;23(1):12-7. https://doi.org/10.1111/ j.1751-7117.2008.07275.x.

70. Goebel JR, Doering LV, Lorenz KA, Maliski SL, Nyamathi AM, Evangelista LS. Caring for special populations: total pain theory in advanced heart failure: applications to research and practice. Nurs Forum. 2009;44(3):175-85. https://doi.org/10.1111/j.1744-6198. 2009.00140.x.

71. Goodlin SJ, Wingate S, Albert NM, Pressler SJ, Houser J, Kwon J, et al. PAIN-HF investigators. Investigating pain in heart failure patients: the pain assessment, incidence, and nature in heart failure (PAIN-HF) study. J Card Fail. 2012;18(10):776-83. https://doi. org/10.1016/j.cardfail.2012.07.007.

72. Rustøen T, Stubhaug A, Eidsmo I, Westheim A, Paul SM, Miaskowski C. Pain and quality of life in hospitalized patients with heart failure. J Pain Symptom Manag. 2008;36(5):497-504. https://doi.org/10.1016/j.jpainsymman.2007.11.014.

73. Shah AB, Udeoji DU, Baraghoush A, Bharadwaj P, Yennurajalingam S, Schwarz ER. An evaluation of the prevalence and severity of pain and other symptoms in acute decompensated heart failure. J Palliat Med. 2013;16(1):87-90. https:// doi.org/10.1089/jpm.2012.0248.

74. Godfrey CM, Harrison MB, Friedberg E, Medves JM, Tranmer JE. The symptom of pain in individuals recently hospitalized for heart failure. J Cardiovasc Nurs. 2007;22(5):368-74. https://doi. org/10.1097/01.JCN.0000287035.77444.d9.

75. Light-McGroary K, Goodlin SJ. The challenges of understanding and managing pain in the heart failure patient. Curr Opin Support Palliat Care. 2013;7:14-20. https://doi.org/10.1097/SPC. 0b013e32835c1f2f.X.

76. Park J, Moser DK, Griffith K, Harring JR, Johantgen M. Exploring symptom clusters in people with heart failure. Clin Nurs Res. 2019;28(2):165-81. https://doi.org/10.1177/ 1054773817729606.

77. Easton K, Coventry P, Lovell K, Carter LA, Deaton C. Prevalence and measurement of anxiety in samples of patients with heart failure: meta-analysis. J Cardiovasc Nurs. 2016;31(4):367-79. https://doi.org/10.1097/JCN.0000000000000265.

78. Sokoreli I, Pauws SC, Steyerberg EW, de Vries GJ, Riistama JM, Tesanovic A, et al. Prognostic value of psychosocial factors for first and recurrent hospitalizations and mortality in heart failure patients: insights from the OPERA-HF study. Eur J Heart Fail. 2018;20(4):689-96. https://doi.org/10.1002/ejhf.1112.

79. Vongmany J, Hickman LD, Lewis J, Newton PJ, Phillips JL. Anxiety in chronic heart failure and the risk of increased hospitalisations and mortality: a systematic review. Eur J Cardiovasc Nurs. 2016;15(7):478-85. https://doi.org/10.1177/ 1474515116635923.

80. Rutledge T, Reis VA, Linke SE, Greenberg BH, Mills PJ. Depression in heart failure a meta-analytic review of prevalence, intervention effects, and associations with clinical outcomes. J Am Coll Cardiol. 2006;48(8):1527-37. https://doi.org/10.1016/j. jacc.2006.06.055.

81. Sokoreli I, de Vries JJ, Riistama JM, Pauws SC, Steyerberg EW, Tesanovic A, et al. Depression as an independent prognostic factor for all-cause mortality after a hospital admission for worsening heart failure. Int J Cardiol. 2016;220:202-7. https://doi.org/10. 1016/j.ijcard.2016.06.068.

82. Celano CM, Villegas AC, Albanese AM, Gaggin HK, Huffman JC. Depression and anxiety in heart failure: a review. Harv Rev Psychiatry. 2018;26(4):175-84. https://doi.org/10.1097/HRP. 000000000000162 An excellent review of depression/anxiety in $\mathrm{HF}$.

83. Jiang W, O'Connor C, Silva SG, Kuchibhatla M, Cuffe MS, Callwood DD, et al. Safety and efficacy of sertraline for depression in patients with CHF (SADHART-CHF): a randomized, double-blind, placebo-controlled trial of sertraline for major depression with congestive heart failure. Am Heart J. 2008;156(3):437-44. https://doi.org/10.1016/j.ahj.2008.05.003.

84. Angermann CE, Gelbrich G, Störk S, Gunold H, Edelmann F, Wachter R, et al. Effect of Escitalopram on all-cause mortality and hospitalization in patients with heart failure and depression: the MOOD-HF randomized clinical trial. JAMA. 2016;315(24): 2683-93. https://doi.org/10.1001/jama.2016.7635.

85. Honda S, Nagai T, Sugano Y, Okada A, Asaumi Y, Aiba T, et al. Prevalence, determinants, and prognostic significance of delirium in patients with acute heart failure. Int J Cardiol. 2016;222:521-7. https://doi.org/10.1016/j.ijcard.2016.07.236.

86. Uthamalingam S, Gurm GS, Daley M, Flynn J, Capodilupo R. Usefulness of acute delirium as a predictor of adverse outcomes in patients $>65$ years of age with acute decompensated heart failure. Am J Cardiol. 2011;108(3):402-8. https://doi.org/10.1016/j. amjcard.2011.03.059.

87. Cannon JA, Moffitt P, Perez-Moreno AC, Walters MR, Broomfield NM, McMurray JJV, et al. Cognitive impairment and heart failure: systematic review and meta-analysis. J Card Fail. 2017;23(6):464-75. https://doi.org/10.1016/j.cardfail.2017. 04.007.

88. Levin SN, Hajduk AM, McManus DD, Darling CE, Gurwitz JH, Spencer FA, et al. Cognitive status in patients hospitalized with acute decompensated heart failure. Am Heart J. 2014;168(6):91723. https://doi.org/10.1016/j.ahj.2014.08.008.

89. Cannon JA, Shen L, Jhund PS, Kristensen SL, Køber L, Chen F, et al. Dementia-related adverse events in PARADIGM-HF and other trials in heart failure with reduced ejection fraction. Eur $\mathrm{J}$ Heart Fail. 2017;19(1):129-37. https://doi.org/10.1002/ejhf.687.

90. van der Steen JT, Radbruch L, Hertogh CM, de Boer ME, Hughes JC, Larkin P, et al. European Association for Palliative Care (EAPC). White paper defining optimal palliative care in older people with dementia: a Delphi study and recommendations from the European Association for Palliative Care. Palliat Med. 2014;28(3):197-209. https://doi.org/10.1177/ 0269216313493685 .

91. Butler J, Binney Z, Kalogeropoulos A, Owen M, Clevenger C, Gunter D, et al. Advance directives among hospitalized patients with heart failure. JACC Heart Fail. 2015;3(2):112-21. https://doi. org/10.1016/j.jchf.2014.07.016.

92.• White-Williams C, Rossi LP, Bittner VA, Driscoll A, Durant RW, Granger BB, et al. Addressing social determinants of health in the care of patients with heart failure: a scientific statement from the American Heart Association. Circulation. 2020;141(22):e841-63. https://doi.org/10.1161/CIR.0000000000000767 A wide-ranging paper documenting socio-economic factors influencing those with HF.

93. Sterling MR, Ringel JB, Pinheiro LC, Safford MM, Levitan EB, Phillips E, et al. Social determinants of health and 90-day mortality after hospitalization for heart failure in the REGARDS study. $\mathrm{J}$ Am Heart Assoc. 2020;9(9):e014836. https://doi.org/10.1161/ JAHA.119.014836.

94. Davies JM, Sleeman KE, Leniz J, Wilson R, Higginson IJ, Verne $\mathrm{J}$, et al. Socioeconomic position and use of healthcare in the last year of life: a systematic review and meta-analysis. PLoS Med. 2019;16(4):e1002782. https://doi.org/10.1371/journal.pmed. 1002782.

95. Allana S, Thompson DR, Ski CF, Clark AM. Intersectionality in heart failure self-care: ignorance is not an option. J Cardiovasc Nurs. 2020;35(3):231-3. https://doi.org/10.1097/JCN. 0000000000000661 .

96. Sulmasy DP. A biopsychosocial-spiritual model for the care of patients at the end of life. Gerontologist. 2002;42 Spec No 3:24 33. https://doi.org/10.1093/geront/42.suppl_3.24. 
97. Vollman MW, LaMontagne LL, Wallston KA. Existential wellbeing predicts perceived control in adults with heart failure. Appl Nurs Res. 2009;22(3):198-203. https://doi.org/10.1016/j.apnr. 2008.02.001.

98. Selman LE, Brighton LJ, Sinclair S, Karvinen I, Egan R, Speck P, et al. InSpirit Collaborative. Patients' and caregivers' needs, experiences, preferences and research priorities in spiritual care: a focus group study across nine countries. Palliat Med. 2018;32(1):21630. https://doi.org/10.1177/0269216317734954.

99. Gillilan R, Qawi S, Weymiller AJ, Puchalski C. Spiritual distress and spiritual care in advanced heart failure. Heart Fail Rev. 2017;22(5):581-91. https://doi.org/10.1007/s10741-017-9635-2.

100. Flint KM, Fairclough DL, Spertus JA, Bekelman DB. Does heart failure-specific health status identify patients with bothersome symptoms, depression, anxiety, and/or poorer spiritual well-being? Eur Heart J Qual Care Clin Outcomes. 2019;5(3):233-41. https://doi.org/10.1093/ehjqcco/qcy061.

101. Ross L, Miles J. Spirituality in heart failure: a review of the literature from 2014 to 2019 to identify spiritual care needs and spiritual interventions. Curr Opin Support Palliat Care. 2020;14(1):918. https://doi.org/10.1097/SPC.0000000000000475.

102. United Nations Educational, Scientific and Cultural Organisation (UNESCO). 2020. Cultural diversity. http://www.unesco.org/ new/en/social-and-human-sciences/themes/internationalmigration/glossary/cultural-diversity/. Accessed 18 Aug 2020.

103. Evans N, Meñaca A, Koffman J, Harding R, Higginson IJ, Pool R, et al. Cultural competence in end-of-life care: terms, definitions, and conceptual models from the British literature. J Palliat Med. 2012;15(7):812-20. https://doi.org/10.1089/jpm.2011.0526.

104. Cain CL, Surbone A, Elk R, Kagawa-Singer M. Culture and palliative care: preferences, communication, meaning, and mutual decision making. J Pain Symptom Manag. 2018;55(5):1408-19. https://doi.org/10.1016/j.jpainsymman.2018.01.007.

105. Davidson PM, Phillips JL, Dennison-Himmelfarb C, Thompson SC, Luckett T, Currow DC. Providing palliative care for cardiovascular disease from a perspective of sociocultural diversity: a global view. Curr Opin Support Palliat Care. 2016;10(1):11-7. https://doi.org/10.1097/SPC.0000000000000188 A wellconstructed review of cultural factors relevant to those with cardiovascular disease.

106. Taylor P, Johnson MJ, Dowding DW. Clinical decision-making at the end of life: a mixed-methods study. BMJ Support Palliat Care. 2020;10(3):e26. https://doi.org/10.1136/bmjspcare-2018-001535.

107. Molzahn AE, Sheilds L, Bruce A, Schick-Makaroff K, Antonio M, Clark AM. Life and priorities before death: a narrative inquiry of uncertainty and end of life in people with heart failure and their family members. Eur J Cardiovasc Nurs. 2020;1474515120918355: 147451512091835. https://doi.org/10.1177/1474515120918355.

108. Strömberg A, Jaarsma T. Thoughts about death and perceived health status in elderly patients with heart failure. Eur J Heart Fail. 2008;10(6):608-13. https://doi.org/10.1016/j.ejheart.2008. 04.011.

109. Lowey SE, Norton SA, Quinn JR, Quill TE. A place to get worse: perspectives on avoiding hospitalization from patients with endstage cardiopulmonary disease. J Hosp Palliat Nurs. 2014;16(6): 338-45. https://doi.org/10.1097/NJH.0000000000000081.

110. Gomes B, Calanzani N, Gysels M, Hall S, Higginson IJ. Heterogeneity and changes in preferences for dying at home: a systematic review. BMC Palliat Care. 2013;12:7. https://doi.org/ 10.1186/1472-684X-12-7.

111. Cross SH, Kamal AH, Taylor DH Jr, Warraich HJ. Hospice use among patients with heart failure. Card Fail Rev. 2019;5(2):93-8. https://doi.org/10.15420/cfr.2019.2.2.

112. Blinderman CD, Billings JA. Comfort care for patients dying in the hospital. N Engl J Med. 2015;373(26):2549-61. https://doi.
org/10.1056/NEJMra1411746 An excellent summary of endof-life-care practice for inpatients.

113. Krishnaswami A, Steinman MA, Goyal P, Zullo AR, Anderson TS, Birtcher KK, et al. Deprescribing in older adults with cardiovascular disease. J Am Coll Cardiol. 2019;73(20):2584-95. https://doi.org/10.1016/j.jacc.2019.03.467.

114. Nizamic T, Murad MH, Allen LA, Mcllvennan CK, Wordingham SE, Matlock DD, et al. Ambulatory inotrope infusions in advanced heart failure: a systematic review and meta-analysis. JACC Heart Fail. 2018;6(9):757-67. https://doi.org/10.1016/j. jchf.2018.03.019.

115. Stoevelaar R, Brinkman-Stoppelenburg A, van Driel AG, Theuns DA, Bhagwandien RE, van Bruchem-Visser RL, et al. Trends in time in the management of the implantable cardioverter defibrillator in the last phase of life: a retrospective study of medical records. Eur J Cardiovasc Nurs. 2019;18(6):449-57. https://doi.org/ $10.1177 / 1474515119844660$

116. Kirkpatrick JN, Hauptman PJ, Goodlin SJ. Bundling informed consent and advance care planning in chronic cardiovascular disease: we need to talk. JAMA Intern Med. 2015;175(1):5-6. https://doi.org/10.1001/jamainternmed.2014.6219.

117. Padeletti L, Arnar DO, Boncinelli L, Brachman J, Camm JA, Daubert JC, et al.; Reviewers:, Kirchhof P, Becker R, Cosio F, Loh P, Cobbe S, Grace A, Morgan J; European Heart Rhythm Association; Heart Rhythm Society. EHRA Expert Consensus Statement on the management of cardiovascular implantable electronic devices in patients nearing end of life or requesting withdrawal of therapy. Europace. 2010;12(10):1480-9. https://doi.org/ 10.1093/europace/euq275.

118. Teuteberg JJ, Cleveland JC Jr, Cowger J, Higgins RS, Goldstein DJ, Keebler M, et al. The Society of Thoracic Surgeons Intermacs 2019 annual report: the changing landscape of devices and indications. Ann Thorac Surg. 2020;109(3):649-60. https://doi.org/ 10.1016/j.athoracsur.2019.12.005.

119. Centers for Medicare and Medicaid Services. 2013 Decision memo for ventricular assist devices for bridge-to-transplant and destination therapy (CAG-00432R). https://www.cms.gov/ medicare-coverage-database/details/nca-decision-memo.aspx? NCAId=268. Accessed 9 Sept 2020.

120. Sagin A, Kirkpatrick JN, Pisani BA, Fahlberg BB, Sundlof AL, O'Connor NR. Emerging collaboration between palliative care specialists and mechanical circulatory support teams: a qualitative study. J Pain Symptom Manag. 2016;52(4):491-7.e1. https://doi. org/10.1016/j.jpainsymman.2016.03.017.

121. Dunlay SM, Strand JJ, Wordingham SE, Stulak JM, Luckhardt AJ, Swetz KM. Dying with a left ventricular assist device as destination therapy. Circ Heart Fail. 2016;9(10):e003096. https://doi. org/10.1161/CIRCHEARTFAILURE.116.003096.

122. DeMartino ES, Braus NA, Sulmasy DP, Bohman JK, Stulak JM, Guru PK, et al. Decisions to withdraw extracorporeal membrane oxygenation support: patient characteristics and ethical considerations. Mayo Clin Proc. 2019;94(4):620-7. https://doi.org/10. 1016/j.mayocp.2018.09.020.

123. Baumwol J. "I need help"-a mnemonic to aid timely referral in advanced heart failure. J Heart Lung Transplant. 2017;36(5):5934. https://doi.org/10.1016/j.healun.2017.02.010.

124. Asano R, Abshire M, Dennison-Himmelfarb C, Davidson PM. Barriers and facilitators to a 'good death' in heart failure: an integrative review. Collegian. 2019;26:651-65. https://doi.org/10. 1016/j.colegn.2019.09.010.

Publisher's Note Springer Nature remains neutral with regard to jurisdictional claims in published maps and institutional affiliations. 